\title{
ETA versus Speed
}

\section{Dear Reader,}

As lawmakers in Germany have come under increased pressure to introduce a $130 \mathrm{~km} / \mathrm{h}$ speed limit, it has become increasingly difficult to deny the plausibility of arguments in favor of vehiclebased maximum speed limits that go beyond Volvo's "reasonable" limit of $180 \mathrm{~km} / \mathrm{h}$. Such limits would, after all, help us to achieve our overarching goals of extended EV driving ranges and greater energy efficiency. The simple reason is that lower speeds save energy. Moreover, limiting top speeds would make it easier, especially in the case of EVs, to optimize powertrain and energy conversion efficiency. The term speed limit in this context refers to real, vehicle-based limits, and not to the widespread use of signs on our highways. While some may regard this as a form of socialist intervention, the question is whether we can afford not to do it and whether it really entails a loss of liberty.

Whatever your view may be, reducing maximum speeds would obviously enable us to make swifter progress in the area of vehicle automation. The task of using AI and sensor systems to achieve safe automated driving across a range of 0 to $130 \mathrm{~km} / \mathrm{h}$ is far less daunting than across a range of 0 to $300 \mathrm{~km} / \mathrm{h}$. The benefits would include lower system costs and quicker implementation.

And if an across-the-board regulation of vehicle speeds were to improve traffic flow, then we would get something valuable in exchange: time. Wouldn't it be better, on the way to work, to spend $37 \mathrm{~min}$ in flowing traffic in a self-driving vehicle at a largely constant speed of $30 \mathrm{~km} / \mathrm{h}$ than to spend $48 \mathrm{~min}$ in stopand-go traffic in a non-automated vehicle at speeds of up to $50 \mathrm{~km} / \mathrm{h}$ ? And what if slower speeds are relevant at a societal level? Speeders uninclined to accept the basic tenets of game theory will have to ask themselves whether they would really rather lose $11 \mathrm{~min}$ on their way to work, and another $11 \mathrm{~min}$ on their way home. "Our notion of luxury in the area of urban mobility has already begun to change. What people value now is an improved estimated Time of Arrival (ETA)," Anders Warming from Borgward reminded us in the context of a panel discussion at the 2019 ATZlive Conference on Vehicles of Tomorrow. And yes, this use case is meant to apply initially to the city. More individualized approaches will have to be taken to exurban driving. And it is exactly this diversification that is so characteristic of our efforts to prepare for the future of transportation. It's a big new playing field for engineers and planners willing to think outside the box and help discover new paths forward.

We hope you enjoy reading this latest issue!

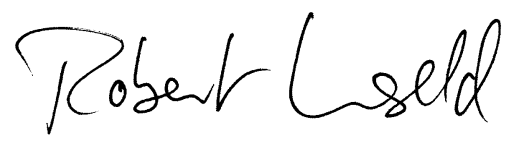

Robert Unseld Responsible Editor

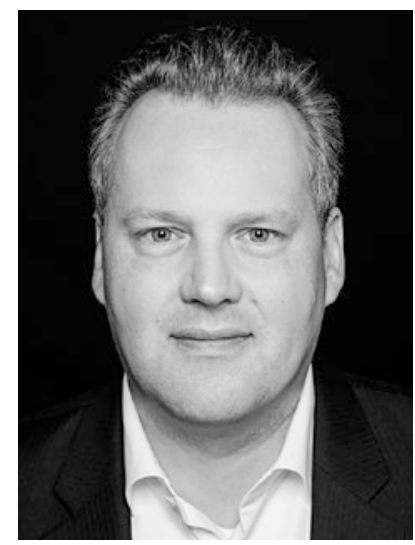

\section{A Sprinkle Here, a Pinch There}

The right testing strategy for every taste.

Automated driving is the soupe du jour on many manufacturers' menus. Of course, it's all about getting the blend right when diverse driving functions interact. Count on our experts to help you cook up a recipe for safety that hits the spot. They know to pinpoint, understand and model all the test cases that matter to you. So that a high testing effort is not the fly in the ointment.

ITK Engineering GmbH - Take the fast track to sophisticated solutions.

ww.itk-engineering.com

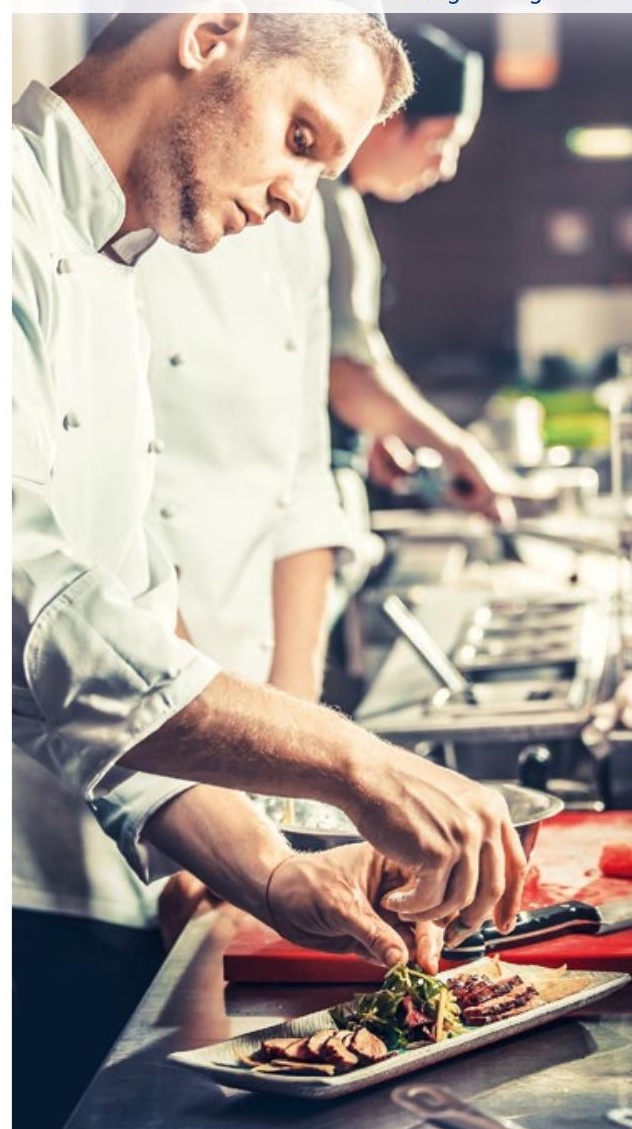

